\title{
PERBANDINGAN KEMAMPUAN MEMBACA CEPAT DENGAN KEMAMPUAN MEMBACA GRAFIK OLEH SISWA KELAS XI SMK SWASTA PAB-2 MEDAN TAHUN PELAJARAN 2017- 2018
}

\author{
Nirmawan \\ Universitas Muslim Nusantara Al-Washliyah Medan \\ Irmanirma90@gmail.com
}

\begin{abstract}
Abstrak
Penulisan ini bertujuan untuk mengetahui Perbandingan Kemampuan Membaca Cepat Dengan Kemampuan Membaca Grafik Oleh Siswa Kelas XI SMK Swasta PAB-2 Medan Tahun Pembelajaran 2017/2018. Populasi penelitian ini adalah siswa kelas XI SMK Swasta PAB-2 Medan Tahun Pembelajaran 2017 - 2018 yang berjumlah 160 siswa yang terdiri dari 4 kelas. Kemudian untuk menentukan sampel digunakan teknik random. berdasarkan undian yang dilakukan terpilih 40 orang sebagai sampel penelitian.Metode yang digunakan dalam penelitian ini adalah metode eksperimen yaitu metode yang dilakukan dengan mengadakan pengamatan secara teliti terhadap objek tersebut. penulis menggunakan alat pengumpul data berupa tes, yaitu tes esai.Pengolahan analisis data dilakukan dengan menggunakan rumus uji-t. yaitu untuk mengetahui berapa besar pengaruh variabel $x$ dan variabel $y$. dan dari hasil penelitian dapat diketahui bahwa hipotesis diterima, karena $t$ hitung $>t_{\text {tabel }}(1,99<3,29>2,64)$, maka hipotesis yang berbunyi "Terdapat Perbedaan Membaca Cepat dengan Membaca Grafik " dapat diterima.
\end{abstract}

Kata kunci : membaca cepat dan membaca grafik

\begin{abstract}
Abstrack
This writing is aimed for knowing the Comparison of Ability in Fast Reading by Reading the Graphic of Students XI Vocational School PAB 2 Medan 2017-2018. This population research is for students XI Vocational school PAB-2 Medan 2017-2018 that has 160 student which is consit 4 classes. Then, taking a sample by using random technique, based on the choice of 40 students as the sample research. The used method in research is experiment method. It is method that is done by researching detail to the object. The writer used the collected tools such as test, essay test. Analizing the data is done by using the patter test- $t$, it is for knowing how many influences the $x$-variable dan from the result of research can know the accepted hypothesis because $t_{\text {hitung }}>t_{\text {tabel }}(1,99<3,29>2,64)$, so the hypothesis said "There are Comparisons Fast Reading by Reading the Graphic" can accepted.
\end{abstract}

Key word: fast reading dan reading the graphic

\section{PENDAHULUAN}

\subsection{Latar Belakang}

Keterampilan bahasa perlu ditingkatkan, salah satunya adalah membaca, karena membaca adalah salah satu komunikasi tulis yang sangat penting bagi manusia. Tapi kenyataannya saat ini pembelajaran membaca di sekolah menengah cenderung kurang diperhatikan. Dalam perakteknya di sekolahsekolah, Belajar membaca hanya 
meliputi kegiatan membaca (bersuara atau dalam hati) dan menjawab semua pertanyaan tentang isi bacaan. Terkadang anak-anak juga sulit untuk memahami antara membaca cepat dengan membaca grafik. Dalam hal ini guru sebagai motivator harus dapat menjelaskan secara baik antara membaca cepat dan membaca grafik. Dengan seringnya siswa melakukan latihan secara berulangulang diharapkan siswa dapat memahami antara membaca cepat dengan membaca grafik tersebut. Kemampuan membaca cepat dengan membaca grafik merupakan tujuan pokok agar siswa mampu memahami kemampuan membaca. Sasaran ini diharapkan dapat dicapai melalui penjelasan dari guru antara membaca cepat dengan membaca grafik. Yang dimaksud dengan membaca cepat adalah membaca dengan kecepatan yang tinggi tetapi memahami ide pokok dan makna bacaan. Dengan membaca cepat tersebut diharapkan siswa mampu memahami makna bacaan secara baik tanpa memerlukan waktu yang lama. Jadi jika menghadapi ujian siswa mampu menjawab pertanyaan secara cepat. Berhubungan dengan pernyataan di atas, peneliti beranggapan bahwa siswa akan lebih memahami isi bacaan dengan membaca cepat dan membaca grafik. Dengan demikian dapaat mengubah pengetahuan yang dimiliki siswa, namun yang menjadi permasalahan sejauh mana kemampuan siswa untuk mampu membedakan membaca cepat dengan membaca grafik.

\subsection{Tujuan}

Tujuan penulisan ini adalah untuk mengetahui Untuk mengetahui hasil kemampuan membaca cepat dan membaca grafik siswa beserta kemampuan siswa dalam membandingkan pemahaman dalam membaca cepat dan grafik oleh siswa kelas XI SMK PAB-2 Medan Tahun Pembelajaran 2016/2017.

\subsection{Pendekatan Pemecahan Masalah \\ Pendekatan pemecahan masalah penulisan ini adalah menggunakan model pembelajaran membaca dalam hati yaitu model pembelajaran yang digunakan pada kegiatan membaca cepat dan membaca grafik.}

\section{METODE}

Metode yang digunakan dalam penelitian ini adalah metode eksperimen yaitu metode yang dilakukan dengan mengadakan pengamatan secara teliti terhadap objek tersebut. Adapun langkahlangkah metode eksperimen antara lain :

\section{TABEL 2.1}

\section{LANGKAH-LANGKAH METODE EKSPERIMEN}

\begin{tabular}{|c|l|l|}
\hline Waktu & \multicolumn{1}{|c|}{ Kelas Membaca cepat } & \multicolumn{1}{|c|}{ Kelas Membaca Grafik } \\
\hline Pertemuan I & $\begin{array}{l}\text { Diberi teks wacana untuk di analisis oleh } \\
\text { setiap siswa }\end{array}$ & $\begin{array}{l}\text { Memberikan teks wacana untuk di } \\
\text { analisis melalui membaca grafik }\end{array}$ \\
\hline Pertemuam II & $\begin{array}{l}\text { Berdasarkan teks wacana siswa disuruh } \\
\text { membaca berdasarkan waktu yang sudah } \\
\text { ditentukan } \\
\text { Lalu guru menghitung berapa kecepatan } \\
\text { masing-masing anak }\end{array}$ & $\begin{array}{l}\text { Guru memberikan penjelasan tentang } \\
\text { pengertian grafik, jenis-jenis grafik } \\
\text { Guru memberikan teks mengenai bacaan } \\
\text { grafik dan siswa menganalisis isi grafik } \\
\text { tersebut }\end{array}$ \\
\hline Pertemuan III & $\begin{array}{l}\text { Latihan menentukan kecepatan pada } \\
\text { membaca cepat }\end{array}$ & $\begin{array}{l}\text { Latihan untuk menyimpulkan isi dari } \\
\text { grafik }\end{array}$ \\
\hline
\end{tabular}




\section{HASIL DAN PEMBAHASAN}

Untuk memperoleh data, penulis menggunakan tes esai. Dengan instrumen tersebut diperoleh data untuk variabel $\mathrm{X}_{1}$ membaca cepat dan data variabel $\mathrm{X}_{2}$ dengan membaca grafik. Setelah dilakukan penelitian tentang perbandingan kemampuan membaca cepat dengan kemampuan membaca grafik oleh siswa kelas XI SMK Swasta PAB-2 Medan tahun pelajaran 2016/2017 maka diperoleh hasil sebagai berikut

\section{Merumuskan data variabel $X_{1}$ ( membaca cepat ) dan variabel $X_{2}$ ( membaca grafik)}

TABEL.3.1

NILAI SISWA MEMBACA CEPAT

\begin{tabular}{|c|c|c|c|}
\hline No & Nama Siswa & Skor & Nilai \\
\hline 1 & Ahmad Rahafi & 10 & 50 \\
\hline 2 & Edy Satria & 11 & 55 \\
\hline 3 & Tri Mulyadi & 12 & 60 \\
\hline 4 & Fajaruddin & 14 & 70 \\
\hline 5 & Johan Simima & 14 & 70 \\
\hline 6 & Sulaeman & 16 & 80 \\
\hline 7 & Rahmad Yunus & 10 & 50 \\
\hline 8 & Ismail Asbari & 14 & 70 \\
\hline 9 & Chairil Anwar & 15 & 75 \\
\hline 10 & Dwi Andiki & 12 & 60 \\
\hline 11 & Ali Alatas & 16 & 80 \\
\hline 12 & Azhari & 15 & 75 \\
\hline 13 & Bayu Sandika & 16 & 80 \\
\hline 14 & Maulana & 10 & 50 \\
\hline 15 & Rizky & 13 & 65 \\
\hline 16 & Muliadi & 16 & 80 \\
\hline 17 & Ardiansyah & 11 & 55 \\
\hline 18 & Sutrisno & 11 & 55 \\
\hline 19 & Ejer Simbolon & 10 & 50 \\
\hline 20 & Apriadi Silalahi & 10 & 55 \\
\hline 21 & Andri Tito & 13 & 65 \\
\hline 22 & Irfan & 10 & 50 \\
\hline 23 & Ismail & 14 & 70 \\
\hline 24 & M. Afandi & 11 & 55 \\
\hline 25 & M.Elmi & 15 & 75 \\
\hline 26 & M. Hatta & 11 & 55 \\
\hline 27 & Ramadanil & 13 & 65 \\
\hline 28 & Utha Masturi & 14 & 70 \\
\hline 29 & Yudi Pratama & 16 & 80 \\
\hline 30 & Zulkarnain & 15 & 75 \\
\hline 31 & Ahmad Zulfikar & 14 & 70 \\
\hline 32 & Ari Prasetyo & 14 & 70 \\
\hline 33 & Arif Famuji & 11 & 55 \\
\hline 34 & Darwisman & 15 & 75 \\
\hline 35 & Dian Anjani & 13 & 65 \\
\hline 36 & Rizki Utama & 13 & 65 \\
\hline 37 & Rizki Gundari & 15 & 75 \\
\hline 38 & Roy Nababan & 13 & 65 \\
\hline 39 & M. Afandi & 12 & 60 \\
\hline 40 & Yosi Tansia & 11 & 55 \\
\hline
\end{tabular}

TABEL.3.2

NILAI SISWA MEMBACA GAFIK

\begin{tabular}{|c|c|c|c|}
\hline No & Nama Siswa & Skor & Nilai \\
\hline 1 & Ahmad Rahafi & 12 & 60 \\
\hline
\end{tabular}




\begin{tabular}{|c|c|c|c|}
\hline 2 & Edy Satria & 13 & 65 \\
\hline 3 & Tri Mulyadi & 15 & 75 \\
\hline 4 & Fajaruddin & 15 & 75 \\
\hline 5 & Johan Simima & 12 & 60 \\
\hline 6 & Sulaeman & 15 & 75 \\
\hline 7 & Rahmad Yunus & 13 & 65 \\
\hline 8 & Ismail Asbari & 16 & 80 \\
\hline 9 & Chairil Anwar & 16 & 80 \\
\hline 10 & Dwi Andiki & 12 & 60 \\
\hline 11 & Ali Alatas & 16 & 80 \\
\hline 12 & Azhari & 17 & 85 \\
\hline 13 & Bayu Sandika & 16 & 80 \\
\hline 14 & Maulana & 12 & 60 \\
\hline 15 & Rizky & 14 & 70 \\
\hline 16 & Muliadi & 17 & 85 \\
\hline 17 & Ardiansyah & 14 & 70 \\
\hline 18 & Sutrisno & 18 & 90 \\
\hline 19 & Ejer Simbolon & 17 & 85 \\
\hline 20 & Apriadi Silalahi & 12 & 60 \\
\hline 21 & Andri Tito & 18 & 90 \\
\hline 22 & Irfan & 14 & 70 \\
\hline 23 & Ismail & 12 & 60 \\
\hline 24 & M. Afandi & 12 & 60 \\
\hline 25 & M.Elmi & 15 & 75 \\
\hline 26 & M. Hatta & 13 & 65 \\
\hline 27 & Ramadanil & 14 & 70 \\
\hline 28 & Utha Masturi & 13 & 65 \\
\hline 29 & Yudi Pratama & 15 & 75 \\
\hline 30 & Zulkarnain & 14 & 70 \\
\hline 31 & Ahmad Zulfikar & 13 & 65 \\
\hline 32 & Ari Prasetyo & 15 & 75 \\
\hline 33 & Arif Famuji & 15 & 75 \\
\hline 34 & Darwisman & 13 & 65 \\
\hline 35 & Dian Anjani & 14 & 70 \\
\hline 36 & Rizki Utama & 15 & 75 \\
\hline 37 & Rizki Gundari & 14 & 70 \\
\hline 38 & Roy Nababan & 14 & 70 \\
\hline 39 & M. Afandi & 15 & 75 \\
\hline 40 & Yosi Tansia & 14 & 70 \\
\hline
\end{tabular}

\section{Menganalisis Kemampuan Membaca Cepat}

TABEL.3.3

DISTRIBUSI FREKUENSI VARIABEL X1 ( MEMBACA CEPAT )

\begin{tabular}{|c|c|c|c|c|c|}
\hline $\mathrm{X}$ & $\mathrm{F}$ & $\mathrm{FX}$ & $(\mathrm{X}-\mathrm{X})$ & $\mathrm{X}^{2}$ & $\mathrm{FX}^{2}$ \\
\hline 50 & 5 & 250 & -15 & 225 & 1125 \\
55 & 8 & 440 & -10 & 100 & 800 \\
60 & 3 & 180 & -5 & 25 & 75 \\
65 & 6 & 390 & 0 & 0 & 0 \\
70 & 7 & 490 & 5 & 25 & 175 \\
75 & 6 & 450 & 10 & 100 & 600 \\
80 & 5 & 400 & 15 & 225 & 1125 \\
\hline & $\mathbf{4 0}$ & $\mathbf{2 6 0 0}$ & & & $\mathbf{3 9 0 0}$ \\
\hline
\end{tabular}

\section{Rata- rata}

$\mathrm{N}=39$

$\Sigma \mathrm{X}=2600$

$\mathrm{M}=\frac{\sum x}{N}=\frac{2600}{40}=65$ 
2. Standar deviasi

$$
\begin{aligned}
\qquad \mathrm{fx}^{2}=3900 & \\
\mathrm{SD}_{\mathrm{x}}=\frac{\sqrt{\sum f x^{2}}}{N} & =\frac{\sqrt{3900}}{40}=\sqrt{97,5}=9,87 \\
& =\frac{S D}{\sqrt{N-1}} \\
& =\frac{9,87}{\sqrt{39}} \\
& =\frac{9,87}{6,24} \\
& =1,58
\end{aligned}
$$

\begin{tabular}{|c|c|c|c|c|c|}
\hline Y & $\mathrm{F}$ & FY & $(\mathrm{Y}-\mathrm{Y})$ & $\mathrm{Y}^{2}$ & $\mathrm{FY}^{2}$ \\
\hline 60 & 7 & 420 & $-11,75$ & 138,06 & 966,42 \\
\hline 65 & 6 & 390 & $-6,75$ & 45,56 & 273,36 \\
\hline 70 & 9 & 630 & $-1,75$ & & \\
\hline 75 & 9 & 675 & 3,25 & 3,06 & 27,54 \\
\hline 80 & 4 & 320 & 8,25 & & \\
\hline 85 & 3 & 255 & 13,25 & 10,56 & 95,04 \\
\hline \multirow[t]{5}{*}{90} & 2 & 180 & 18,25 & & \\
\hline & & & & 68,06 & 272,24 \\
\hline & & & & 175,56 & 526,68 \\
\hline & & & & 333,06 & 666,12 \\
\hline & 40 & 2870 & & & 2827,4 \\
\hline
\end{tabular}

3. Menganalisis Kemampuan Membaca Grafik

TABEL.3.4

DISTRIBUSI FREKUENSI VARIABEL $X_{2}$ ( MEMBACA GRAFIK )

Dari data di atas dapat dicari rata-rata, standar deviasi yaitu :

\section{Rata-rata}

$$
\begin{aligned}
& \mathrm{N}=39 \\
& \sum \mathrm{y}=2870 \\
& \mathrm{M}=\frac{\sum y}{N}=\frac{2870}{40}=71,75
\end{aligned}
$$

2. Standar Deviasi

$$
\begin{aligned}
& \sum \mathrm{fx}^{2}=2827,4 \\
& \mathrm{SD}=\frac{\sqrt{\sum f x^{2}}}{N}=\frac{\sqrt{2827,4}}{40}=\sqrt{70,68}=8,4
\end{aligned}
$$

3. $\mathrm{SE}_{M 1}$

$$
\begin{aligned}
=\frac{S D}{\sqrt{N-1}} \\
=\frac{8,4}{\sqrt{39}}
\end{aligned}
$$




$$
\begin{aligned}
& =\frac{8,4}{6,24} \\
& =1,34
\end{aligned}
$$

4. Mencari Standar Error Perbedaan Mean Variabel $X_{1}$ dan Variabel $X_{2}$

$$
\begin{aligned}
\mathrm{SE}_{M 1-M 2} & =\sqrt{S E_{M 1}^{2}+S E_{M 2}^{2}} \\
& =\sqrt{(1,58)^{2}+(1,34)^{2}} \\
& =\sqrt{2,49+1,79} \\
& =\sqrt{4,24} \\
& =2,05
\end{aligned}
$$

5. Pengujian Persyaratan Analisis dilakukan dengan menguji data normalitas variabel penelitian.

TABEL.3.5

UJI NORMALITAS DATA (VARIABEL $\mathrm{X}_{1}$ )

DENGAN UJI LILIEFORS

\begin{tabular}{|c|c|c|c|c|c|c|}
\hline $\mathrm{X}$ & $\mathrm{F}$ & $F_{\text {kum }}$ & $z_{i}$ & $F_{(z i)}$ & $S_{(z i)}$ & $F_{(z i)}-S_{(z i)}$ \\
\hline 50 & 5 & 5 & $-1,51$ & 0,0655 & 0,125 & 0,0595 \\
\hline 55 & 8 & 13 & $-1,01$ & 0,1564 & 0,325 & $\mathbf{0 , 1 6 8 6}$ \\
\hline 60 & 3 & 16 & $-0,51$ & 0,305 & 0,4 & 0,095 \\
\hline 65 & 6 & 22 & 0 & 0,5 & 0,55 & 0,05 \\
\hline 70 & 7 & 29 & 0,51 & 0,695 & 0,725 & 0,03 \\
\hline 75 & 6 & 35 & 1,01 & 0,8436 & 0,875 & 0,031 \\
\hline 80 & 5 & 40 & 1,51 & 0,9345 & 1 & 0,0655 \\
\hline
\end{tabular}

Berdasarkan tabel di atas, harga yang paling besar di antara harga-harga mutlak selisih tersebut $\left(L_{o}\right)=$ 0,1686. $L_{o}$ tabel dengan $\mathrm{n}=40$ pada taraf signifikan $\alpha 0,05(95 \%)=$ 0,886 . dengan demikian dapat disimpulkan $L_{o}$ hitung $<L_{o}$ tabel $(0,1686<0,886)$, hal ini membuktikan populasi berdistribusi normal.

TABEL.3.6

UJI NORMALITAS DATA (VARIABEL $\mathbf{X}_{2}$ ) DENGAN UJI LILIEFORS

\begin{tabular}{|c|c|c|c|c|c|c|}
\hline $\mathrm{X}$ & $\mathrm{F}$ & $F_{\text {kum }}$ & $z_{i}$ & $F_{(z i)}$ & $S_{(z i)}$ & $F_{(z i)}-S_{(z i)}$ \\
\hline 60 & 7 & 7 & $-1,39$ & 0,0823 & 0,175 & 0,0927 \\
\hline 65 & 6 & 13 & $-0,80$ & 0,2119 & 0,325 & 0,1131 \\
\hline 70 & 9 & 22 & $-0,21$ & 0,4168 & 0,55 & $\mathbf{0 , 1 3 3 2}$ \\
\hline 75 & 9 & 31 & 0,39 & 0,6517 & 0,775 & 0,1233 \\
\hline 80 & 4 & 35 & 1,46 & 0,9279 & 0,875 & 0,0529 \\
\hline 85 & 3 & 38 & 1,56 & 0,9406 & 0,95 & 0,0094 \\
\hline 90 & 2 & 40 & 2,17 & 0,985 & 1 & 0,015 \\
\hline
\end{tabular}

Berdasarkan tabel di atas, harga yang paling besar diantara harga-harga mutlak selisih tersebut $\left(L_{o}\right)=$ 
0,1332. $L_{o}$ tabel dengan $\mathrm{n}=40$ pada taraf signifikan $\alpha 0,05 \quad(95 \%)=$ 0,886 . dengan demikian dapat disimpulkan $L_{o}$ hitung $<L_{o}$ tabel $(0,1332<0,886)$, hal ini membuktikan populasi berdistribusi normal.

\section{KESIMPULAN.}

Berdasarkan hasil dan pembahasan tersebut dapat disimpulkan adanya perbedaan yang signifikan antara hasil kemampuan membaca cepat dengan hasil kemampuan membaca grafik. Hal ini dibuktikan berdasarkan perhitungan diketahui kemampuan membaca cepat berada pada tingkat cukup atau dengan nilai rata-rata 65 , sedangkan kemampuan membaca grafik berada pada tingkat baik atau dengan nilai rata-rata 71,75 .

\section{DAFTAR PUSTAKA}

Arsyad, azhar. 2002. Media Pembelajaran. Jakarta: Grapindo Depdiknas. 2005. Kamus Besar Bahasa Indonesia. Jakarta: Balai Pustaka

Harjasujana. 1996. Kamus Besar Bahasa Indonesia. Jakarta: Balai Pustaka

Koentjaraningrat. 1991. Metodemetode Penelitian masyarakat. Jakarta: Gramedia

Kosasih dan Joko Mumpuni. 2005. Bahasa Indonesia. Jakarta: Priranri Darma Kalokatama

Poewadarminta, W.J.S. 1986. Kamus Umum Bahasa Indonesia. Jakarta: Bina Aksara

Sadirman, Aroief, dkk. 1996. Media Pendidikan. Jakarta: Raja grafindo Prasada

Soedarso. 2005. Speed Reading Sistem Membaca Cepat dan Efektif. Jakarta: Gramedia Pustaka Umum
Sudjana. 2002. Metode Statistik. Bandung Tarsito

Susilo Adi Setyawan. 2009. @yahoo.com

Tarigan, HG. 1987. Membaca Sebagai Suatu Keterampilan Berbahasa. Bandung: Angkasa

P. U. Sitohang, Dra. 2003. Matematika. Medan: Untuk Kalangan Sendiri

Wahyudin. 2005. Bahasa Indonesia. Bandung: Regina 